\title{
Elia Saneleuterio (Ed.). La agencia femenina en la literatura ibérica y latinoamericana. Madrid/Frankfurt am Main: Iberoamericana/ Vervuert, 2020, 382 páginas
}

Jorge Chen Sham

Chen Sham, J. (2022). Elia Saneleuterio (Ed.). La agencia femenina en la literatura ibérica y latinoamericana. Madrid/Frankfurt am Main: Iberoamericana/ Vervuert, 2020, 382 páginas. Revista de Filología y Lingüística de la Universidad de Costa Rica, 48(1), e48271. doi: https://doi.org/10.15517/rfl.v48i1.48271

\section{(9) $\mathbb{P Q \Theta \Theta}$}

Doi: https://doi.org/10.15517/rfl.v48i1.48271

URL: https://revistas.ucr.ac.cr/index.php/filyling/index 
Revista de Filología y Lingüística de la Universidad de Costa Rica

ISSN: 0377-628X

ISSN: 2215-2628

filyling@gmail.com

Universidad de Costa Rica

Costa Rica

Elia Saneleuterio (Ed.). La agencia femenina en la literatura ibérica y latinoamericana. Madrid/Frankfurt am Main: Iberoamericana/ Vervuert, 2020, 382 páginas

\section{Chen Sham, Jorge}

Elia Saneleuterio (Ed.). La agencia femenina en la literatura ibérica y latinoamericana. Madrid/Frankfurt am Main: Iberoamericana/ Vervuert, 2020, 382 páginas

Revista de Filología y Lingüística de la Universidad de Costa Rica, vol. 48, núm. 1, e48271, 2022

Universidad de Costa Rica, Costa Rica

Disponible en: https://www.redalyc.org/articulo.oa?id=33268016005

DOI: https://doi.org/10.15517/rfl.v48i1.48271

\section{(c) (1) $\Theta$}

Esta obra está bajo una Licencia Creative Commons Atribución-NoComercial-SinDerivar 3.0 Internacional. 
Elia Saneleuterio (Ed.). La agencia femenina en la literatura ibérica y latinoamericana. Madrid/Frankfurt am Main: Iberoamericana/ Vervuert, 2020, 382 páginas

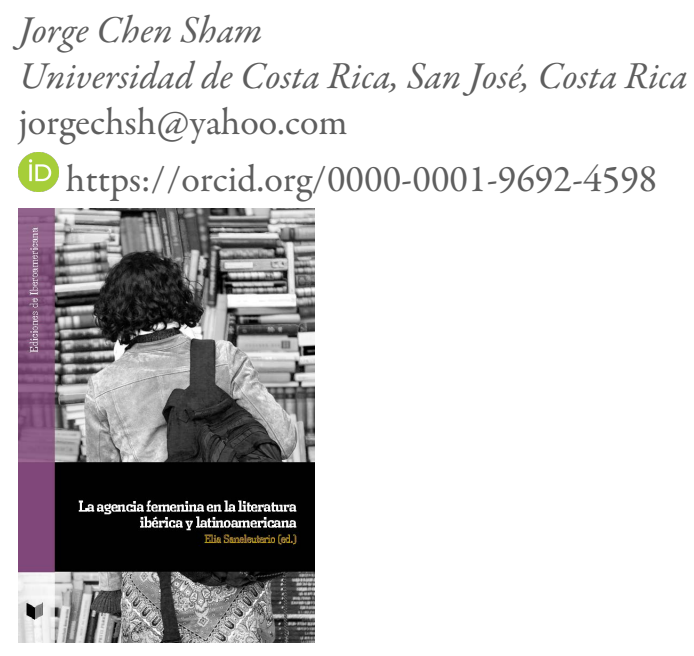

DOI: https://doi.org/10.15517/rfl.v48i1.48271

Redalyc: https://www.redalyc.org/articulo.oa? $\mathrm{id}=33268016005$

Saneleuterio Elia. La agencia femenina en la literatura ibérica y
latinoamericana. 2020. Madrid/Frankfurt am Main. Iberoamericana/
Vervuert. 382pp.

En primer lugar, me llama la atención que el primer trabajo, de la editora del volumen, Elia Saneleuterio, no se presente como una introducción al volumen; lo segundo, que aborde como su título lo indica "Escritoras españolas e hispanoamericanas de todos los siglos y la agencia femenina en los personajes de ficción” (p. 13), una restricción sobre el corpus de escritores por abordar (así con un sustantivo colectivo), por cuanto se ocupa también de autores masculinos y en general, de la representación cultural de la mujer en cuanto "objeto" y "sujeto", de sus modelos de ficción y del papel que tales ejercen sobre el desarrollo de un campo de acciones que rebasa la literatura y el arte en tanto agenda ética y feminista que busca la igualdad de géneros. Aquí remite a las propuestas de Judith Butler y a promover esa reflexión que cuestione e invisibilice los ámbitos de la cultura y el saber que genera unos condicionamientos sobre la mujer y su definición sociocultural (p. 14). Ahora bien, si bien es cierto, la "agencia", constructo basado en la categoría gramatical del "agente", deriva en una nueva promoción del decir, pensar y hacer de un personaje femenino, se le olvida a Elia Saneleuterio reconocer el origen de tal concepto de "agencia" dentro de los programas narrativos de Argildas Greimas y de los que trabajaron en torno a él para establecer una tipología de la semántica narrativa. Por lo demás, el artículo funciona como una verdadera introducción que pone a dialogar los artículos del volumen y explica, más allá de un mero resumen de cada propuesta, sus alcances, para que le quede al lector la interrogante de si no hay una evolución diacrónica y sincrónica en la manera en que tanto escritores, hombres como mujeres, abordan y tratan a los personajes protagónicos femeninos, porque hay autores de diversa época y de diferentes países, así como respuestas a la "agencia” cuando hay conciencia y se cataliza una agenda cultural o de género. Esas serán cuestiones que tendrán que dilucidarse a mediano plazo.

El artículo inicial lo firma Begoña Souviron López con el título de "El estudio de la responsividad en las voces femeninas de la literatura clásica” (pp. 27-45). El neologismo, acuñado por Iris Zavala a partir de Mijaíl Bajtín/Valentín Voloshinov en su teoría dialógica de la palabra, implica una respuesta ética, es decir, una toma de posición para que se problematice su carácter conflictivo, acentuado y polémico dentro de la interacción social (lástima que no se vaya a la fuente primaria). Tal referencia es la que retoma Souviron López para incorporarla en una ginocrítica que cuestione el "signo" mujer, el discurso patriarcal y las nuevas reivindicaciones que interpela, problematiza y construye ese "signo". A esto alude el concepto 
de responsividad, para que ella ponga atención en las intervenciones orales de personajes femeninos y en las fórmulas explícitas de su registro en tanto escucha y alocución hacia el oyente en muestras de la literatura medieval y del siglo XVI español. Sin ninguna perspectiva teórica clara al respecto, en "Baste ya de rigores: Sor Juana Inés de la Cruz desde el género", Emilio Ruiz Serrano et al. se interesan por aportar a la crítica de la monja novohispana dentro de una revisión de algunos de los tópicos conocidos sobre su posición hacia las mujeres (pp. 47-65). Hubiera sido más provechoso para ahondar, haber solo retomado el famoso poema "Hombres necios que acusáis" y proponer una nueva lectura, pues invierte la diatriba contra las mujeres de la literatura medieval.

El recorrido del callejeo urbano por el Madrid decimonónico, que propone Pilar Úcar Ventura de la mano de personajes femeninos de Pérez Galdós en "Heroínas literarias de Galdós: una propuesta didáctica paseando por Madrid" (pp. 67-81), se nutre de esos papeles que la sociedad tradicional ha impuesto en el tópico "ángel del hogar" (p.72) y que ella desea inscribir en el movimiento urbano, con el fin de observar cómo interactúa el personaje con la realidad y el flujo propio de las calles, de personas, de tiendas y establecimientos. Úcar Ventura apenas lo esboza, porque material suficiente tenía para que Fortunata y Benigna, por ejemplo, la guiaran y viéramos tanto la "sociabilidad" como la "socialidad" en perspectiva, constituyentes de ese tejido social en donde comportamientos y hasta la mirada de los personajes están determinados social y culturalmente. En la misma línea que el anterior artículo, Maríacarmela Ucciardello retoma el devenir de la mujer casada en "Matrimonio, sexualidad y lujuria en la España decimonónica según una perspectiva burguesa: Tristana y Rosalía, el declive del ángel de hogar" (pp. 83-100). Dentro del discurso patriarcal, el espacio de lo doméstico y la potestas maritalis que promueven los códigos sociales circunscriben a la mujer casada a ennoblecer y a enriquecer el "patrimonio", que los manuales y las revistas ilustradas codifican para luego denostar a la "coqueta" y derrochadora, mientras los tratados médicos insisten en las diferencias anatómicas y en una salud para la procreación. Así, Pérez Galdós con Tristana y Rosalía respectivamente, cuestiona la figura angelical de la mujer y nos presenta a una "mujer varonil”, que no se adapta al modelo. Se trata de un artículo bien planteado y coherente, pero a la hora de mostrar esta "agencia” en la descripción y conformación del personaje, hay que ver a estas "heroínas" pensar, actuar, sentir (no solamente a través de un discurso referido, sino de un primer plano para ser coherente con las propuestas de género) y esto solamente se puede hacer si les damos lugar en los textos literarios, en sus palabras y en su discurso, para ser congruentes con esta nueva propuesta del libro y que la gran mayoría de los trabajos del volumen abordan con menor o mayor éxito.

En "María Eugenia contra sí misma: el intento frustrado de empoderamiento en Ifigenia, de Teresa de la Parra” (pp. 101-120), María José Jorquera Hervás sí que construye ese proceso de concientización fracasado, puesto que no lleva a la protagonista de Teresa de la Parra a la real emancipación, porque, como dice la sabiduría popular, "del dicho al hecho hay mucho trecho" y del "deber ser" (p. 105) al "hacer", el personaje se decanta por el ensimismamiento y la frivolidad; la educación y la cultura refinada se devuelven contra María Eugenia, coqueta y consumista, tal y como se presenta el modelo de "esposa", que se silencia y se proyecta en una literatura del yo para asumir y callar frente a esas presiones sociales a la mujer y, como la portadora del nombre de Ifigenia, pretende rebelarse contra las leyes y el orden pero cede ante la moral y la falsedad. Alejandra Karina Carballo visibiliza a una escritora poco conocida en "Reclamos de una libertaria: naturalismo y proyecto educativo en El libro bumilde y doliente, de Salvadora Medina Onrubia” (pp. 121-141). El libro de cuentos, publicado en 1918, por la maestra rural de la Provincia de Entre Ríos, Argentina, se ajusta a los cánones del positivismo en esa relación del medio y de lo social, de modo que apuesta crudamente por la denuncia de las desigualdades sociales; su confesión de "sinceridad visceral" en el prólogo autorial es el asidero de un estudio profundo del espacio rural con rasgos naturalistas, al crear personajes de niños y adultos "como incapaces de luchar" (p. 129), de tísicos y alcohólicos, de campesinas explotadas dentro de una degeneración biológica y social, en la que las taras, el alcohol y las enfermedades pululan con el contraste entre el campo y la ciudad. Como se puede observar, es un artículo 
que no se circunscribe a los personajes femeninos, cuando tenía material suficiente con las madres tísicas o las campesinas para hacerlo. El trabajo sobre la poeta uruguaya Ida Vitale de Sally Abdalla Wahdan ofrece un análisis sugestivo y profundo sobre las tendencias ecocríticas en su poesía; pero ¿cómo encaja en un libro sobre "la agencia" femenina, esta es una pregunta insoslayable cuando se plantea una temática y una metodología como la que se presenta en el título del libro. Así, "La ecoliteratura de Ida Vitale: Un espacio para la intimidad y la sabiduría” (pp. 143-167) subraya la acción poético-ambiental (p. 162) en la que inserta el hablante lírico (no hay marcas de género ni tampoco Abdalla Wahdan lo aclara) su diálogo vehemente y su "poder hacer", volviendo a una categoría agentiva como respuesta a la degradación alarmante del Planeta en tanto conciencia de figura autorial.

Enfocándose aún más en ese paso transmedial de un relato como el de Julio Baquero Cruz, del "El árbol azul" (2009) a la película El olivo (2016), de la directora española Icíar Bollaín, Isabel Cuñado sí que se plantea, dentro del tópico de la España vacía y del nuevo ruralismo en auge actualmente, la suerte de un olivar y la defensa del olivo por parte de un colectivo de mujeres. En "El olivo es sagrado: ecofeminismo y nuevo ruralismo en El olivo y "El árbol azul”" (pp. 169-184) no solo tiene un enfoque feminista, sino que la ecología es una práctica de resistencia que se inscribe en la focalización y el centralismo que posee Alma, quien da cohesión y vertebra la película en su empeño por conservar la memoria familiar y la defensa del olivar (p. 181), como una reivindicación del colectivo de mujeres. De igual modo, Laura Margarita Febres de Ayala se enfoca en la adscripción cultural y religiosa en "La mujer judía en dos novelas latinoamericanas: La piel del alma, de Teresa Porzecansky, y Tela de sevoya (sic), de Myriam Moscona” (pp. 187-201). Es un artículo muy breve y pone a dialogar a dos escritoras, la primera uruguaya cuya novela se construye con una trama policiaca y es de 1996, mientras que la segunda es mexicana y su texto es más reciente, del 2012 y narra la historia de una familia sefardí. Su punto de conexión es la estructura patriarcal sobre la que se fundamenta el judaísmo (a pesar de que sea la madre la que herede su adscripción y pertenencia), para que la reclusión y la soledad sean las marcas más ostensibles de una dominación que tiene sus resquicios en la memoria y la transmisión de la palabra, reductos de la mujer en la tradición semita. En "Maternidad y acción en Historia de una maestra, de Josefina Aldecoa” (pp. 203-2012), Aranzasu Sumalla apenas le dedica unas líneas a una novela y a una figura, la de la maestra, que tiene mucho que contarnos desde el punto de vista de una "vocación" y las maneras de afirmar y hacer coexistir la vida profesional y la familiar, cuando el tipo de "la maestra" es la de la solterona en nuestra tradición hispánica y aquí se exponen, en esta novela del año 1990, las trampas de la maternidad en el marco de la Guerra Civil.

Los trabajos que vienen a continuación se preocupan más por ir a la relación entre el proyecto autorial de la "escritora" y sus concepciones de "mujer", que ponen en práctica en su escritura en tanto agenda cultural y política. La conciencia de las diferencias genéricas y sexuales son las que desarrolla Belén Hernández Marzal en "Retrato de la mujer creadora en La loca de la casa, de Rosa Montero" (pp. 213-229), para retomar esa mala conciencia de Montero sobre su rechazo a ser "catalogada como autora de literatura femenina" (p. 213) y la exposición de la problemática de la mujer creadora retomando este título ya programático de la agencia femenina centrándose en las esferas de acción de la mujer escritora a partir del siglo XIX. Por su parte, en "Música de ópera de Soledad Puértolas: contrapunto de voces de mujer" (pp. 231-240), Francisca González Arias sí que convence en su interesante estudio sobre un linaje femenino, cuya matriarca, doña Elvira, se embarca, desde ese matrimonio acomodado y burgués, a la "búsqueda de su propia voz" (p. 233), legando unas cartas a su sobrina Valentina y a su nieta Alba, cuya onomástica ya resuena en la configuración de una "intrahistoria", creíble y pertinente. Esto permite entroncar con los siguientes artículos, en donde la importancia de la literatura infantil y juvenil se hace ostensible, para crear modelos positivos y configurar historias desde una versión femenina. En "La literatura infantil en Puerto Rico: la transgresión femenina/ feminista en Rosario Ferré” (pp. 241-257), Rocío Arana y María Caballero Wangüemert abordan a la puertorriqueña desde ese cuestionamiento que ella hace al mundo del cuento de hadas para sabotear al patriarcado. Extraño mucho que no se hayan dedicado a estudiar algunos de sus cuentos más paradigmáticos, 
porque priva en ellos "la falsedad de los códigos y patrones socioculturales tradicionales" (p. 253), que niños y mujeres experimentan, para que estos relatos sean nunca "ejemplares". También Sara Vicente Mendo se detiene en la literatura infantil y juvenil en "Personajes femeninos en la narrativa de Graciela Montes: modelos de una sociedad sin miedo” (pp. 259-280), en donde el rasgo más inequívoco de la agencia femenina sea el siguiente, los personajes femeninos "tienen un reto que superar, que es vencer el miedo" (p. 263) hacia los monstruos que pueblan el mundo de la infancia. Excelente artículo, bien desarrollado, dentro de la temática que anunciaba el libro. De igual manera, Anja Rothenburg en "Polizón del Ulises, de Ana María Matute. Trayectoria de un cuento infantil en el franquismo" (pp. 281-299), nos ofrece un estudio sobre El polizón del Ulises (1965), escrito por la española y con el cual se consagra en este género. Se trata de un relato de aprendizaje, gracias a la cual el personaje Jujú se inscribe dentro de una estructura de aventuras, muy propio de la literatura juvenil y enmarcada en la posguerra civil; ahora bien, Rothenburg no explicita la relación con la temática del libro.

Las últimas tres contribuciones sí que interesan más desde la configuración de personajes femeninos. María del Carmen Ramos Cambero se propone el análisis la figura de la heroína en esa irrupción con fuerza del género con la serie de Harry Potter o la saga de Crepúsculo (p. 304), en "La identidad femenina en la novela juvenil de fantasía a través de dos sagas españolas" (pp. 301-319). Resuenan con fuerza el caso de Laura Gallego con sus Alas de fuego (2004) y su continuación en Alas negras (2009), centradas en el protagonismo de una "mujer ángel", Ahriel, sus aventuras y pruebas iniciáticas para configurarse como una heroína fuerte y valerosa, mientras que Susana Vallejo sorprende con su saga de Porta Coeli (2008-2010), novela estructurada en cuatro libros, con el protagonismo de Yebra, una joven, que se encuentra en el camino con Nuño y Bernardo en su búsqueda del unicornio; periplo que explota el mundo de fantasía de castillos, figuras legendarias y aventuras medievales, en donde Vallejo juega también con la distopía, recurriendo a la ciencia y tecnología (p. 314) y que Ramos Cambero define como propio de "la fantasía épica juvenil" (p. 315). En "La narrativa juvenil de Maite Carranza en el siglo XXI: tipología de mujeres protagonistas” (pp. 321-337), Moisés Selfa Sastre se adentra en el mundo narrativo de esta española, ganadora de múltiples premios y gran conocedora del género y repasa los grandes títulos de su producción, aunque nos queda debiendo porque promete una tipología (y esta palabra alude a una clasificación de rasgos que no encuentro), porque lo que hay es un recuento en las conclusiones. El artículo de Begoña Regueiro es de los más interesantes del volumen con el título de "El reciclaje de los cuentos tradicionales y populares en los Cuentos clásicos feministas, de Ángela Vallvey. Una mirada posfeminista y posdigital a la tradición” (pp. 339-357), porque bajo el alero del término "reciclaje" se fundamenta una propuesta ética y política de sabotear el "cuento tradicional" en una colección que ya presenta un gesto de ruptura, "clásicos" y "feministas" van de la mano, para que Vallvey responda a un efecto del reconocimiento (solamente de "querer ser" y "parecerse" retomando modalidades semánticas de la acción) y terminen sus textos por ofrecer "la lucha contra la opresión y alienación femeninas" (p. 345). El último trabajo, firmado por la editora del libro (Saneleuterio), escudriña una figura que ha pasado desapercibida en la narrativa en "La influencia de la tía soltera en las novelas de protagonización femenina" (pp. 359-373) y analiza el complejo actorial y de conducta de personajes como las tías Gertrudis, Angustias o Concha, solamente para citar a las más conocidas en la literatura española del siglo XX. Ella concluye en el establecimiento de un "arquetipo de una identidad femenina individual y satisfecha" (p. 371). 